\title{
Adenoid Basal Carcinoma of Uterine Cervix: A Case Report
}

\author{
İlker SELÇUK ${ }^{1}$, Murat ÖZ ${ }^{1}$ Levent SİRVAN², Tayfun GÜNGÖR ${ }^{1-3}$, Mehmet Mutlu MEYDANLI ${ }^{1}$ \\ Ankara, Turkey
}

\begin{abstract}
Adenoid basal carcinoma of uterine cervix is a very rare entity that has been reported less than 100 cases in the literature. Although the origin of the carcinoma is controversial; the multipotential basal cell layer of cervix is the believed part for tumor growth. A 54 years-old white postmenopausal woman was referred to our clinic with the complaint of postmenopausal bleeding. Her pelvic examination revealed a tumor lesion of $1.5 \mathrm{~cm}$ on the ectocervix. Her cervical and endometrial biopsies revealed an epithelial carcinoma and we performed a radical hysterectomy with bilateral salpingo-oophorectomy and bilateral pelvic-paraaortic lymph node dissection. The final pathology result revealed adenoid basal carcinoma. Distinction of adenoid basal carcinoma from adenoid cystic carcinoma and other aggressive basaloid pathologies of cervix is important for the clinical management of patients since adenoid basal carcinoma is benign in behaviour despite being a carcinoma.
\end{abstract}

Keywords: Adenoid basal carcinoma, Cervical, Human papillomavirus

Gynecol Obstet Reprod Med 2016;22(3):174-176 DOI: 10.21613/GORM.2016.483

\section{Introduction}

Adenoid basal carcinoma $(\mathrm{ABC})$ of uterine cervix is a rare tumor that generally occurs in postmenopausal women. ABCs are commonly asymptomatic and they are usually detected incidentally after hysterectomy (1). ABCs are less than $1 \%$ of all cervical malignancies and there are less than 100 cases in English literature (2) since its first description by Baggish and Woodruff in 1966 (3). ABC of uterine cervix is a tumor with good prognosis and it has some specific characteristics for diagnosis (4). Moreover preoperative cytologic assessment frequently shows high grade squamous intraepithelial lesions. Here, we report a case of $\mathrm{ABC}$ of uterine cervix with diagnostic pitfalls.

\section{Case Report}

A 54 years-old white postmenopausal woman was referred to our clinic with the complaint of postmenopausal bleeding. Her pelvic examination showed a tumoral lesion of $1.5 \mathrm{~cm}$ on the ectocervix. Her cervical smear result was high grade squamous intraepithelial lesion. Her colposcopy directed cervical

\footnotetext{
I Zekai Tahir Burak Women's Health Education and Research Hospital, Gynecologic Oncology Unit and ${ }^{2}$ Pathology Unit, Ankara ${ }^{3}$ Department of Obstetrics and Gynecology, Hitit University Faculty of Medicine, Çorum

Address of Correspondence: Ilker Selçuk

Gynecologic Oncology Unit Zekai Tahir Burak Women's Health Education and Research Hospital Ankara, Turkey ilkerselcukmd@hotmail.com

Submitted for Publication: $\quad$ 16. 02. 2015

Accepted for Publication: 23. 03. 2015
}

: This case report was presented as a poster presentation at the Congress of International Gynecological Cancer Society Melbourne, Australia 2014 biopsy showed atypical squamous cells and it was in debate over a carcinoma in situ or an invasive squamous carcinoma. Her endometrial biopsy result was invasive squamous cell carcinoma which directs the clinician towards a cervical carcinoma with the comment of pathologist. Her pelvic examination under general anesthesia showed intact parametriums. By these findings we performed a radical hysterectomy with bilateral salpingo-oophorectomy and bilateral pelvic-paraaortic lymph node dissection. The final pathology result revealed adenoid basal carcinoma with negative surgical borders and there was not any lymph node metastasis out of 61 total nodes. The tumor was primarily localized to the ectocervix and invading endocervical tissue minimally. It was $1.4 \times 0.4 \mathrm{~cm}$ in diameter and her paracervical lymph nodes and parametriums were without tumor involvement. Lympho-vascular space invasion was not detected. Microscopically we found tumor cells in nests of fibrous stroma with peripheral palisading pattern of basaloid cells (Figure 1, 2, 3).

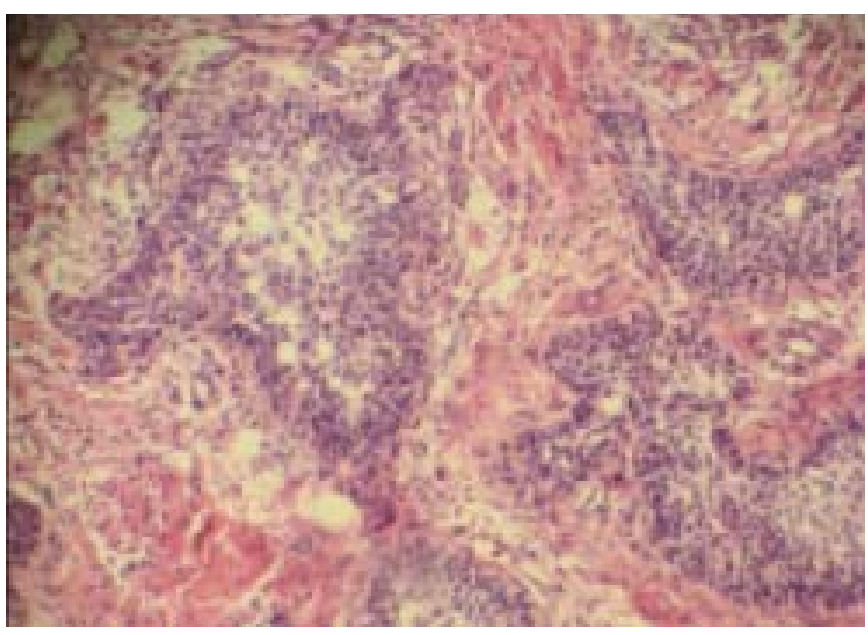

Figure 1: Tumor cells rounded with fibrous stroma with peripheral palisading basaloid cells (HEx10) 


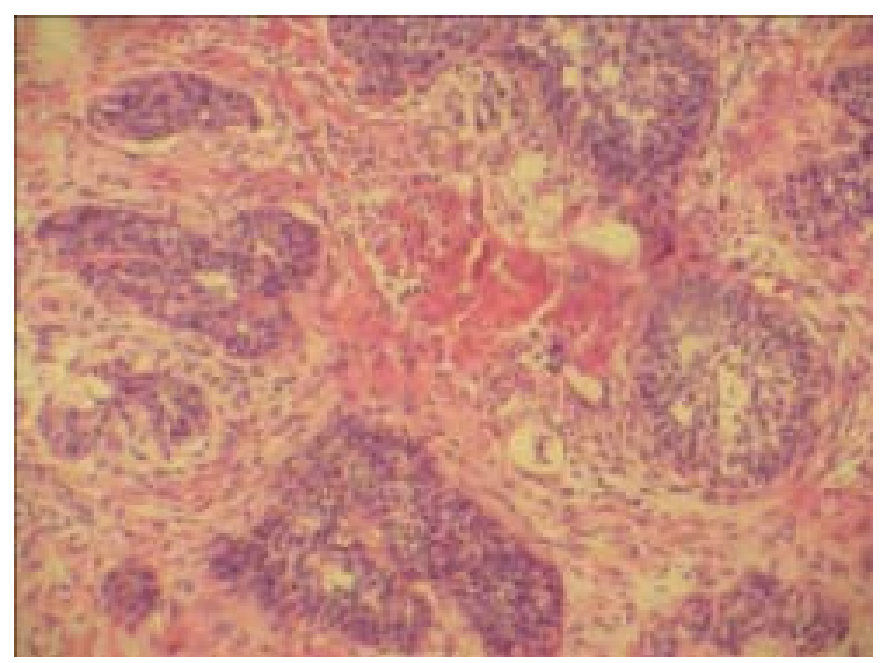

Figure 2: Microcystic structures in the center of basaloid cell groups (HEx20)

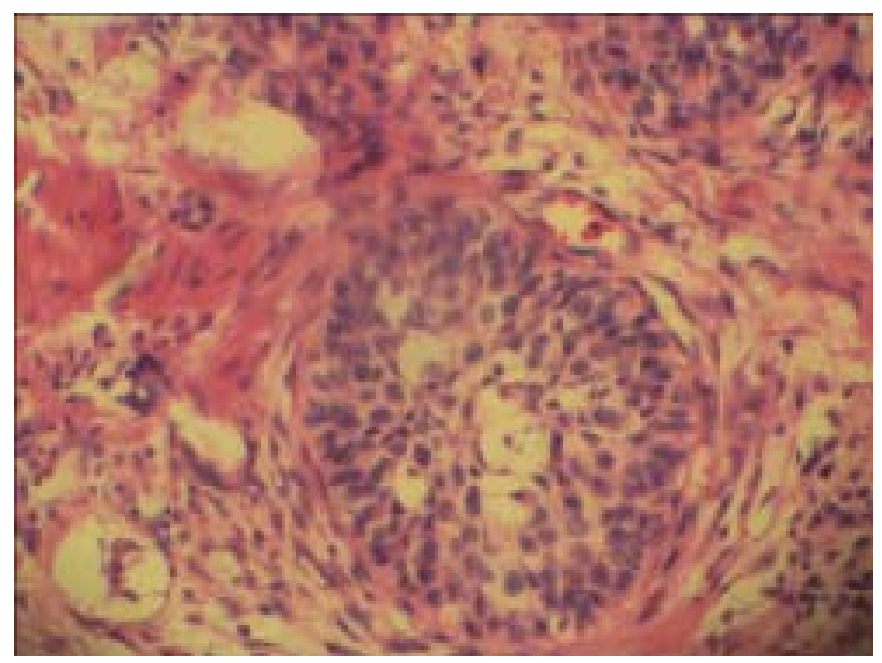

Figure 3: Basaloid tumor cells with a narrow cytoplasm and pleomorphic round nucleus surrounded with peripheral palisading pattern (HEx40)

We did not recommend any adjuvant therapy. Ten months after initial surgery the patient is well without any sign of recurrences.

\section{Discussion}

There are multiple types of basaloid pathologies related with uterine cervix (adenoid basal lesions, adenoid basal hyperplasia, adenoid basal carcinoma, adenoid cystic carcinoma, basaloid squamous cell carcinoma, etc.) and they have different prognostic outcomes. The real incidence for them is not known. However, case series show that they are $<\% 1$ of all cervical malignancies. $\mathrm{ABC}$ of cervix is a rare tumor that there are controversies regarding the origin of tumor. Adenoid basal carcinoma of uterine cervix was hypothesized to derive from the multipotential basal or reserve cell layer of cervical epithelium (5). This cell type could produce solid, trabecular, adenoid structures and by the way the tumor mass is supposed to be originated from immature cells rather than the differen- tiated squamous and/or epithelial cells (6). Microscopically, $\mathrm{ABC}$ is composed of basaloid cells in nests with a peripheral palisading pattern $(7,8)$.

The similar histopathologic features of basaloid lesions directed us on the distinction of $\mathrm{ABC}$ from other pathologies. Adenoid cystic carcinoma (ACC) and basaloid squamous cell carcinoma (BSCC) could mimic ABC, however they are aggressive basaloid pathologies. Adenoid cystic carcinoma and adenoid basal carcinoma share multiple common features that they are often confused. Nevertheless identifying the difference between $\mathrm{ACC}$ and $\mathrm{ABC}$ is important for the prognosis and has a considerable clinical importance. Although $\mathrm{ABC}$ is a tumor with benign potential; ACC is an aggressive tumor and is often complicated with local recurrences and distant metastasis (9). Recently we have learned that these two entities originate from reserve cells; on the other hand differential diagnosis between them is possible clinically, pathologically and immunohistochemically (10). Human papillomavirus is the mainstep for the development of these two tumors $(11,12)$ and discrimination is best made by morphologic evaluation. PAS-diastase stain and alcian blue stain without hyaluronidase pretreatment is important for extracellular basement membranelike material (BMM), which is nearly pathognomonic for ACC. Immunohistochemistry is also limited in diagnosis except type IV collagen and laminin positivity for extracellular BMM in ACC (13).Additionally CK14, CK17, CK19, cytokeratin KL1 and epithelial membrane antigen (EMA) could be found in immunohistochemical stains of $\mathrm{ABC}$ (8). In addition to this classical data, C117 a type III receptor tyrosine kinase protein which is a product of c-kit protooncogene is a promising marker for differentiating $\mathrm{ABC}$ of uterine cervix from $\mathrm{A}^{\mathrm{CC}}(14)$.

Physiologically multipotential reserve cells take part in the squamous metaplasia during reproductive years and basal reserve cells are involved in this proliferation and maturation process during the formation of cervical squamous epithelium. Basal reserve cells are found close to squamo-columnar junction and endocervical glandular cells $(15,16)$. The origin of $\mathrm{ABC}$ was demonstrated to develop from HPV infection, especially HPV 16 and characterized by p53 gene alterations (17); and because of the multipotential reserve cells and HPV; coexistance of other cervical malignities with $\mathrm{ABC}$ can also be detected (1).

Pure $\mathrm{ABCs}$ are usually asymptomatic and gross cervical lesions are not generally detected. However, cervical smears revealing high grade squamous intraepithelial lesions might be the presenting sign of these patients during routine gynecologic examination (7). Additionally, in situ or small invasive squamous cell carcinomas could accompany them (9).ABCs are frequently encountered in postmenopausal black women with a mean age of 63 years (5). DePond et al. (8) defined the youngest patient with adenoid basal carcinoma at 20 years. Our patient was a white 54 years-old woman and presented with postmenopausal bleeding. The lesion was $1.5 \mathrm{~cm}$ in di- 
ameter at the ectocervix and cervical smear result was high grade squamous intraepithelial lesion as described in the literature. We identified the diagnosis of $\mathrm{ABC}$ at the hysterectomy specimen. The final pathology result showed neither lymphovascular space involvement nor lymph node metastasis. It was previously stated in the literature that adenoid basal carcinomas are generally without lymphovascular space invasion with rare mitoses $(5,15)$.

Although ABCs are associated with cervical intraepithelial neoplasias (CIN), in situ or microinvasive squamous cell carcinomas; pure ABCs are a bit different and have a benign behaviour with a very low risk of recurrence and metastasis (18). Indeed adenoid basal epithelioma was thought to replace the terminology of $\mathrm{ABC}$ because of the good prognostic state (19). Grayson and Cooper objected to this claim and proposed that the term adenoid basal epithelioma underestimate the potential role of $\mathrm{ABC}$ (20) because ACC and $\mathrm{ABC}$ have multiple common features and sometimes it is difficult to differentiate these two pathologies. Tumor cells of ABC could be encountered in ACC thus they are combined lesions histopathologically and the hypothesis of transition, from ABC to ACC had proposed $\mathrm{ABC}$ as the precursor lesion of $\mathrm{ACC}$ (13).

In conclusion potential pitfalls regarding not only the preoperative diagnosis of adenoid basal carcinoma but also the distinction of $\mathrm{ABC}$ from adenoid cystic carcinoma and other aggressive basaloid pathologies of cervix are important for the clinical management of patients since ABC is benign in behaviour despite being a carcinoma. However a squamous cell carcinoma may co-exist and may shape the prognosis and survival. A radical surgery relevant with the tumor and co-existing cervical pathology could clarify the lesion and reduce the recurrence risk with negative surgical borders.

\section{References}

1. Lin YC, Perng CL, Chang YM, et al. Coexistent squamous cell carcinoma and adenoid basal carcinoma in the uterine cervix and infection with human papillomavirus (HPV 31). Taiwan J Obstet Gynecol 2013;(3):407-10.

2. Viriyapak B, Park ST, Lee AW, et al. Cervical adenoid basal carcinoma associated with invasive squamous cell carcinoma: a report of rare co-existence and review of literature. World J Surg Oncol 2011 Oct 18;9:132.

3. Baggish MS, Woodruff JD. Adenoid-basal carcinoma of the cervix. Obstet Gynecol 1966;28(2):213-8.

4. Ferry JA. Adenoid basal carcinoma of the uterine cervix: evolution of a distinctive clinicopathologic entity. Int J Gynecol Pathol 1997;16(4):299-300

5. Senzaki H, Osaki T, Uemura Y, et al. Adenoid basal carcinoma of the uterine cervix: immunohistochemical study and literature review. Jpn J Clin Oncol 1997;27(6):437-41.

6. Shilkin KB. Adenoid basal carcinoma of the cervix uteri. J Clin Pathol 1972;25(4):301-5.
7. Russell MJ, Fadare O. Adenoid basal lesions of the uterine cervix: evolving terminology and clinicopathological concepts. Diagn Pathol 2006;1:18.

8. DePond WD, Flauta VS, Lingamfelter DC, et al. Adenoid basal carcinoma of the cervix in a 20 -year-old female: a case report. Diagn Pathol 2006;1:20.

9. Ferry JA, Scully RE. "Adenoid cystic" carcinoma and adenoid basal carcinoma of the uterine cervix. A study of 28 cases. Am J Surgic Pathol 1988;12(2):134-44.

10. Daponte A, Grayson W, Moisuc D, et al. Adenoid cystic carcinoma stage Ib1 treated with radical surgery displaying human papilloma virus 33 (HPV 33): immunoelectron microscopy and review. Gynecol Oncol 2003;90(3):673-6.

11. Grayson W, Taylor L, Cooper K. Detection of integrated high risk human papillomavirus in adenoid cystic carcinoma of the uterine cervix. J Clin Pathol 1996;49(10): 805-9.

12. Grayson W, Taylor LF, Cooper K. Adenoid basal carcinoma of the uterine cervix: detection of integrated human papillomavirus in a rare tumor of putative "reserve cell" origin. Int J Gynecol Pathol 1997;16(4):307-12.

13. Grayson W, Taylor LF, Cooper K. Adenoid cystic and adenoid basal carcinoma of the uterine cervix: comparative morphologic, mucin, and immunohistochemical profile of two rare neoplasms of putative "reserve cell" origin. Am J Surgic Pathol 1999;23(4):448-58.

14. Chen TD, Chuang HC, Lee LY. Adenoid basal carcinoma of the uterine cervix: clinicopathologic features of 12 cases with reference to CD117 expression. Int J Gynecol Pathol 2012;31(1):25-32.

15. Kerdraon O, Cornelius A, Farine MO, et al. Adenoid basal hyperplasia of the uterine cervix: a lesion of reserve cell type, distinct from adenoid basal carcinoma. Hum Pathol 2012;43(12):2255-65.

16. Martens JE, Smedts FM, Ploeger D, et al. Distribution pattern and marker profile show two subpopulations of reserve cells in the endocervical canal. Int J Gynecol Pathol 2009;28(4): 381-8.

17. Jones MW, Kounelis S, Papadaki H, et al. The origin and molecular characterization of adenoid basal carcinoma of the uterine cervix. Int J Gynecol Pathol 1997;16(4):301-6.

18. Takeshima Y, Amatya VJ, Nakayori F, et al. Co-existent carcinosarcoma and adenoid basal carcinoma of the uterine cervix and correlation with human papillomavirus infection. Int J Gynecol Pathol 2002;21(2):186-90.

19. Brainard JA, Hart WR. Adenoid basal epitheliomas of the uterine cervix: a reevaluation of distinctive cervical basaloid lesions currently classified as adenoid basal carcinoma and adenoid basal hyperplasia. Am J Surgic Pathol 1998;22(8):965-75.

20. Grayson W, Cooper K. Adenoid basal epithelioma versus adenoid basal carcinoma. Am J Surgic Pathol 2000;24(2): 313-4. 